\title{
A stepwise daily guide to the KTS Vasculab Debate
}

\section{BB Lee ${ }^{1}$}

1 Professor of Surgery and Director, Center for the Lymphedema and Vascular Malformations, George Washington University, Washington DC, USA Adjunct Professor of Surgery, Uniformed Services University of the Health Sciences, Bethesda, MD, USA Visiting Professor of Surgery, Johns Hopkins University School of Medicine, U.S.A. Emeritus Professor of Surgery, Georgetown University, Washington DC, USA

KTrenaunay Vasculab Debate, held on the Internet, Vasculab List, on May 1-21, 2016. (unmoderated session: May 22-28, 2016.). Discussant: Byung Boong Lee; Moderator: Fausto Passariello; Panel Experts: Miguel Angel Amore, Iris Baumgartner, NingFei Liu, Jovan Markovic, Raul Mattassi, Kurosh Parsi, Massimo Vaghi.

submitted: Mar 29, 2017, accepted: Mar 30, 2017, EPub Ahead of Print: Mar 31, 2017, published: May 1, 2017

Conflict of interest: None

DOI: 10.24019/jtavr.15 - Corresponding author: Prof. Byung Boong Lee, bblee38@comcast.net

(C) 2016 Fondazione Vasculab impresa sociale ONLUS. All rights reserved.

Abstract This paper gathers the suggestions of Prof. BB Lee, the Discussant of the Klippel-Trenaunay Debate, which came up daily beside the participants to help and clarify the issues which showed up during the Debate. The suggestions were provided as letters at each starting point of the Debate and as personalized answers to specific questions.

Keywords Klippel-Trenaunay syndrome; congenital vascular malformations; venous malformations; lymphatic malformations; capillary malformations; AV malformation; Parkes-Weber Syndrome; Hamburg classification; Hemolymphatic malformation; 'Extratruncular and Truncular' type

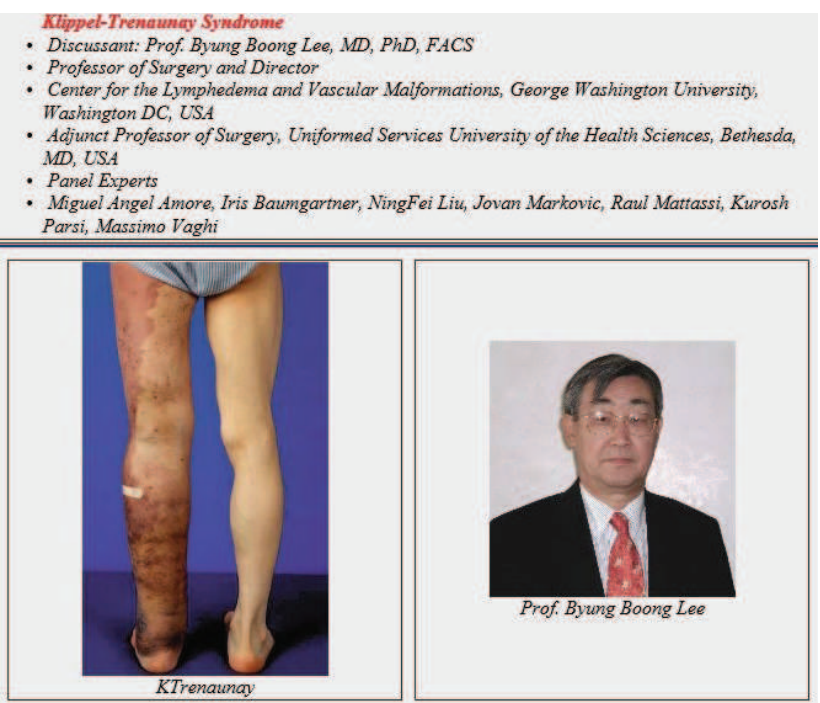

Figure 1 - The KTrenaunay webpage. DOI: 10.24019/2016.KTrenaunay

\section{Introduction - May 1}

Dear Vasculab subscribers,

It is a great privilege for me to share our hard-earned knowledge not only on the Klippel-Trenaunay syndrome (KTS) but the congenital vascular malformations (CVMs) across the board through Vasculab.

I would like to thank first to Dr. Fausto Passariello, Moderator of this unique group/Vasculab, to giving us, myself and invited panelists, for this opportunity to present/ discuss various issues involved to KTS despite the majority of this group/members has more interests on other popular venous issues.

Indeed, the major issue of KTS is venous disorders since various venous malformations (VMs) (e.g. marginal vein; femoral vein hypoplasia; iliac vein aplasia) are heavily engaged to such unique condition together with lymphatic malformations (LMs). But not many of phlebology 
practitioners seem to be keenly aware how close their daily practice is to this potential risk, and inadvertently stepped in the middle of mine field of CVMs with surprise.

So we would like to support/guide you to get through this mine field, and further to show you how to defuse the mine safely if you wish. Hence, on behalf of the panel discussants, we wish you to bring up any issue, not only of the KTS but also all other CVMs so that we could share our humble experiences with you through this unique opportunity for the next three week period.

As Moderator Fausto already posted, we will arbitrarily divide three week period assigned for KTS to assign one topic for a week for convenience sake:

\section{Topics in KTS Debate}

1. Definition \& Classification-anatomy, embryology, patho-physiology, hemodynamics, and genetics

2. Diagnostic Strategy including differential
diagnosis
- 3. Management $\quad$ Strategy: Medical,
endovascular and surgical management and its
complications

For this unique group of Vasculab, we invited SEVEN experts on many different issues involved to KTS as our panelists: Drs. Iris Baumgartner (Switzerland), NingFei Liu (China), Jovan Markovic (USA), Raul Mattassi (Italy), Kurosh Parsi (Australia), Miguel Amore(Argentina) and Massimo Vaghi (Italy).

Indeed, we intentionally selected/invited only 7 among the colleagues with quite diversified background as well as specialty so that the discussion will become livelier. I am sure many of you know them well through their publications through the consensuses as well as the handbooks in this unique field of CVM. But I will make a brief introduction on seven stars.

Mme Iris Baumgartner of Bern Univ who is not only big chair of huge angiology department but also de facto leader to organizing the CVM session to set a new trend in Europe through Charing X Symposium every year. Currently, Iris works closely with Prof. Raul Mattassi and other senior experts of CVMs to strengthen her fantastic multidisciplinary team.

Mme NingFei Liu is current president of ISL (International Society of Lymphology) but known more as tough(?) plastic surgeon in Shanghai to lead a huge group/ department devoted to the lymphedema. Indeed, she is one of few lymphatic reconstruction surgeons in the world we all trust to providing reliable data. Besides, her pioneering work on MR lymphangiography to establish as a clinical tool is legendary.
Massimo Vaghi is rather better known for his enormous capacity/knowledge as an editor through 'Atlas of CVM and Hemangioma' he organized with Raul Mattassi. Now, he took over such prestigious Garbagnate program of CVM, Raul and Prof. Belov established many decades ago. He is a real expert to organize the group to lead the consensus and indeed, without his initiation/help, the IUAISVI Consensus for Vascular Anomaly many of you are familiar with would have not been completed.

Kurosh Parsi is a world renown dermatologic surgeon from Sidney, Australia as you all know, specialized in CVMs and hemangioma with enormous clinical and research background as well. I had a special privilege to take advantage of him as my right arm partner whenever I had to organize any big CVM project through years since he is a genuine perfectionist. He is now a vice president of IUP and will organize IUP World Congress in Melbourne in 2018 and would become de facto leader of the society with no doubt.

Jovan Markovic of Duke University is, as I teased, my most favorite young activist(?) with full of passion and enthusiasm, working with his chairwoman Cynthia Shortell as her right arm to lead famous CVM Center/program of Duke Univ. Jovan is the only person I envy most what Cinny has and I steal his experts especially his fresh idea whenever I have a chance.

Miguel Amore of Univ of Buenos Aires is one of few jewels I found among Latin American colleagues and I am trying to engage more actively in these days through a few joint projects with him. Miguel is a disciple of famous Prof. Ciucci and has simply fascinating cadaver lab no one I know of can match, with enormous data I try to introduce to Anglophone society now. He is currently works with his mentor, Cristobal Papendieck as future leader of CVM as well as lymphology field in Latin America. Indeed, Miguel is the only one young executive board member of ISL if I know correct as only hope for new young blood transfusion ISL needs badly.

Lastly, Raul Mattassi, my life time partner, would not need any introduction to make it redundant but Raul is one of legendary trio together with Dirk Loose and the late Prof. Stefan Belov to establish Hamburg Classification. Indeed, when I got the first 1 million US dollar grant from SamSung Conglomerate back in 1994 as the seed money(?) to organize CVM Center -as the price/compensation to organize American surgery program/system for Korean people through SamSung Medical Center as a joint project of SungKyunKwan Univ/Johns Hopkins Univ-, the first thing I requested was to travel to visit/meet this trio! Since then, Raul has remained as my loyal comrade with unlimited support for the last three decades.

So, we encourage Vasculab members to bring any question directed to any of the panelists if they would. 
Indeed, we welcome any questions, requests, and opinions from the Members, including clinical cases.

\section{Definition - May 1-8, 2016}

We all agree that name-based eponyms like 'KlippelTrenaunay Syndrome' or 'Parkes-Weber Syndrome' gave us a tremendous contribution to understand the bizarre nature of congenital vascular malformation (CVM) through the last century. Indeed, before the modern technology became available to identify complex nature of the CVMs involved, two French physicians, Maurice Klippel and Paul Trenaunay (1900) documented this unique condition for the first time ONLY based on available clinical findings/observation: port wine stain (capillary malformations) and soft tissue and bone hypertrophy, and atypical, mostly lateral varicosity, known as famous clinical triad of KTS. 'Klippel-Trenaunay Syndrome (KTS)' has become a hall mark of CVMs through the last century; it is still most popular 'name based' nosology among many similar syndrome-based descriptions of complicated birth defects involving the circulation system. However, such syndrome-based description has generated substantial confusion because name-based terminology as a "syndrome" failed to differentiate various anatomoclinical pictures with a proper definition of pathogenic role of the vascular abnormality, of its evaluation, and of therapeutic possibilities as correctly pointed by Prof. E. Malan (1974). KTS, for example, failed to accommodate the lymphatic malformation (LM) condition which is an essential CVM component of KTS its initial document as well. And this LM condition was subsequently added to venous malformation (VM) and capillary malformation (CM) to complete its classical description as a syndrome. Besides, substantial confusion on the definition of KTS from the outset still remains with argument on vascular malformation components of the KTS, claiming for extending its vascular malformation component to $\mathrm{AV}$ malformation (AVM) as an extra component in addition to the classical triad of the CM, VM, and LM, despite orthodoxy interpretation of this condition as 'Parkes-Weber Syndrome (PWS). Indeed, as Prof. Raul Mattassi raised the questions on KTS versus PWS through previous workshop for the consensus we already published, there are quite a few questions remained to be answered for the further clearance;

\section{KTS definition issues}

Only lower limbs or also upper one?

Also other sites (head, thorax, buttocks.)?

What about "incomplete cases": only 2 signs of the triad (no nevus, no limb overgrowth, no visible dysplastic veins)?

Is lymphatic involvement mandatory?

- What about AV malformation without overgrowth or nevus?
However, we consider the definition of KTS by Mulliken et al (2005) as "A capillary-lymphatic-venous malformation associated with soft tissue/skeletal hypertrophy, usually to one or more limbs and sometimes the trunk" will be the most accurate interpretation so far. Therefore, previously crucial role of such name-based eponyms/ classification became obsolete now for the understanding of such complex nature of the CVMs, failing to meet the mandate as a new classification for contemporary concept of the CVMs and became the symbol of the old concept with the historical merit for the 'angiodyplasia' era. Although the old concept based on a name-based terminology still remains a significant source of confusion, a new concept based on the Hamburg classification cleared unwanted confusion generated by old concept and identified the vascular malformation components of KTS as a Hemolymphatic Malformation (HLM), providing proper etio-anatomo-pathophysiology of each CVM component to clear the inherent confusion. When the HLM is consisted of VM and LM in addition to CM, it would be interpreted as CVM component of KTS; when the HLM has AVM as one more vascular malformation component in addition to VM and LM, this condition is compatible to the PWS. Notwithstanding, it is still noteworthy to understand the exact nature of so called KTS because this unique syndrome represents a combined condition of CVMs as primary lesions and various abnormal conditions in the soft tissue, bone and/or varicose veins as 'secondary phenomena/ outcome of CVMs' in addition to defective development of other tissues/organs as well. I therefore, do NOT advocate total removal of good old term, KTS from our essential armamentarium to fight the CVMs but claim its 'discriminating' use. The term KTS per se is nothing wrong! Indeed, it accomplished wonderful mission through the last century, and we still need it to back up the current term whenever needed (e.g. easy start to communicate on the CVM issues with lay persons). I only wish to warn its indiscriminating use would do more harm than good since its critical role for the contemporary management of the CVMs is over. Such useless argument along the definition of various CVMs with name-based eponyms is futile for the modern concept, and discriminating use of this old term KTS versus PWS is advised.

\section{Diagnosis - May 8-16, 2016}

We spent one full week, enough time to touch many critical issues involved to Definition and Classification. Hope it helped you to clear much confusion if not all on the definition of KTS. Since such name-based eponyms always carry inherent confusion including KTS, we adopted a new name/classification for the condition as 'hemolymphatic malformation (HLM)' as one of combined form of the CVMs.

We once again uphold the general consensus on how to define inclusion as well as exclusion criteria for KTS 
and indiscriminating use of this name based eponym was emphatically discouraged. Based on what we discussed through the week, we would like to proceed to the second phase for the diagnostic evaluation so that we could get to the final phase of the management a week later.

The diagnosis of this mixed bag of worms/CVMs is however, not so simple in comparison to one single condition of CVM as 'independent' lesion. But it is not complicated as a rocket science and you could reach the goal based on simple mathematic approach on each CVM component involved to KTS.

As discussed through the last week, we concur the majority of CVM specialists to agree that KTS should have THREE basic CVM components, that is, VM and LM as basic CVM components, and preferably CM as its third CVM. Indeed, we infrequently do bend backward to accommodating only two rather than all three components as KTS. Besides, we feel strong that additional findings along musculoskeletal as well as cutaneous-subcutaneous system, mostly as the secondary phenomena caused by their primary (CVM) lesions, would strengthen the diagnosis of KTS more although they are non-essential further to Gastrointestinal/Genitourinary findings.

Nevertheless, one crucial problem involved to KTS is 'VM and LM' present in TWO entirely different conditions, that is 'Extratruncular and Truncular' type in various combinations among four of them: extratruncular VM \& LM and truncular VM \& LM. All four conditions have completely different behavior as well as different prognosis due to their different embryological characteristics, which is extremely important to the clinicians who manage.

The 'extratruncular' VM/LM represents the group of birth defects as the outcome of developmental arrest affecting venous and lymphatic system during the 'earlier stage' of embryonic life while the vascular system is in the reticular stage. Therefore, extratruncular lesions, either VM or LM, retain the characteristics of the mesenchymal cells (angioblasts) as embryonic tissue remnants of mesodermal origin. It means, they retain the potential power to grow/ proliferate when the condition/milieu is right with sufficient stimulation, internally (e.g. menarche, pregnancy, and hormone) or externally (e.g. trauma, surgery). Therefore, all the extratruncular lesions of VM and LM carry a significant risk of recurrence, especially after suboptimal treatment.

Morphologically, extratruncular lesions present as either a diffuse infiltrating or a limited lesion in the form of amorphous vascular cluster with no direct involvement to named vessels; they cause a mechanical compression to surrounding tissues and organs/systems in addition to its hemodynamic impact.

On contrary, the 'truncular' VM/LM lesions are the outcome of developmental arrest during the 'later stage' of embryogenesis while vascular trunk is formed/matured. Therefore, truncular lesions no longer possess the potential power of the mesenchymal cells to grow and proliferate like extratruncular lesions. But, truncular lesions cause much more serious hemodynamic consequences since the lesions are directly involved to the (named) vessel trunk formation, resulting in defective vessel trunk, either partly (e.g. vein web/crest) or as a whole (e.g. venous aneurysm, hypoplasia/ aplasia). Besides, when embryonic vein should fail to take normal involution and remain through the birth as a persistent fetal remnant (truncal) vessel (e.g. marginal vein; sciatic vein), they will cause quite unique hemodynamic consequences due to coexisting avalvulosis (e.g. chronic venous insufficiency; intravascular/deep vein thrombosis and pulmonary embolism).

Morphologically, truncular VM lesions are further subclassified based on the degrees/extents of developmental defect either as an obstructive or dilated lesion with direct involvement to fully matured/ named vessel, ranging from incomplete or immature lesions (aplasia or hypoplasia) to overdeveloped lesions (hyperplasia) (e.g. agenesis/rudimentary deep vein).

Accordingly, clinical evaluation of this combined form of CVMs should start with careful and thorough history taking and physical examination to look for how many kinds of CVMs (CM, VM, and LM) as well as how many embryological subtypes (extratruncular and/or truncular) should coexist. Based on the clinical findings, clinical investigation should proceed to the next step to confirm and/ or rule out each lesion through due laboratory tests in proper combination.

However, diagnostic evaluation should proceed to identify the CVM components first and then to extend to the assessment of secondary phenomenon caused by primary lesion to establish proper linkage between them (e.g. limb length discrepancy caused by VM; chyluria by LM).

Investigation/confirmation of 'primary' pathology can be made mostly based on various combinations of non- to less-invasive tests. Selective invasive (e.g. arteriography) study is seldom needed for routine diagnosis of HLM but remains essential for the differential diagnosis to rule out an AVM involvement.

$$
\begin{aligned}
& \text { Primary pathology investigations } \\
& \text { - I. Non-to less-invasive study - basic } \\
& \text { (standard) } \\
& \text { - } \quad \text { T1 \& T2 weighted MR image study } \\
& \text { - } \quad \text { Duplex ultrasonography } \\
& \text { - Whole body blood pool scintigraphy } \\
& \text { (WBBPS) } \\
& \text { - RI lymphoscintigraphy }
\end{aligned}
$$




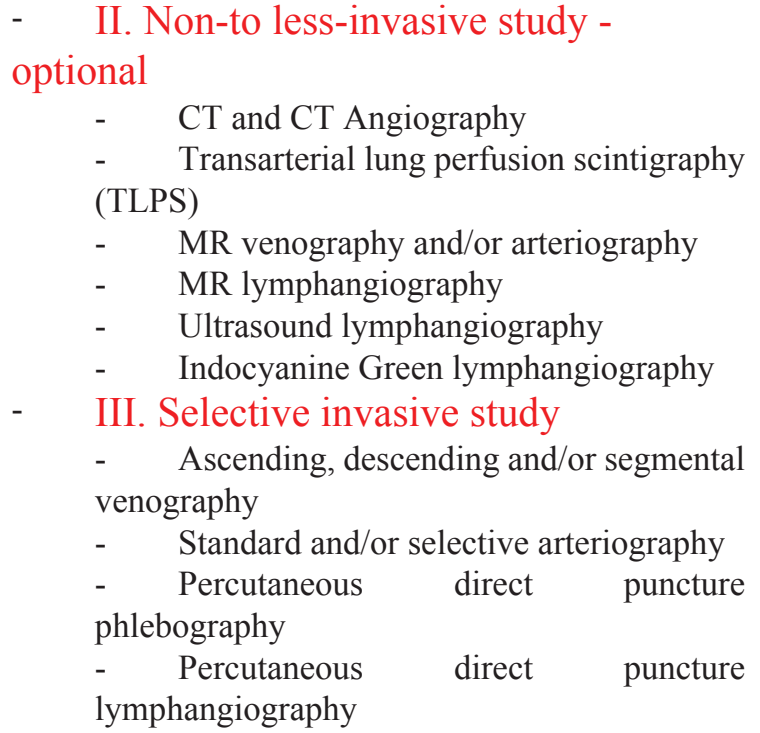

For the investigation of 'secondary' pathology, proper verification and assessment of the direct and/or indirect secondary effects of the primary pathology (VLM) to the various systems should be made;

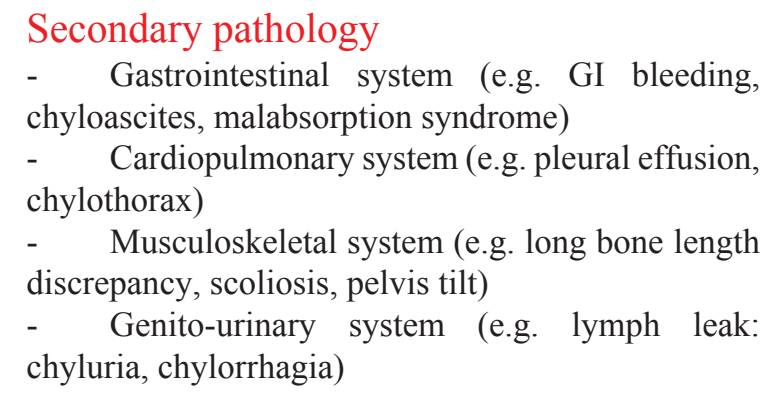

Accurate hemodynamic assessment of the deep venous system of the lower extremity is absolutely mandatory for the safe management of the VM component of KTS, especially before resection of a marginal vein.

\section{Management - May 16-20, 2016}

Today is the first day of the third, last part of KTS Session dedicated for its Management issue. Once again, I would like to thank to Fausto arranging such unique opportunity through Vasculab, sparing full three weeks for KTS alone.

The subject is relatively new to majority of Vasculab subscribers so that we tried hard NOT to waste your precious time for unnecessarily impractical issue but remain to deal with essential basic issues using various references to help better understanding through the week. Those references should be sufficient to give appropriate answer/ explanation on the questions/issues we could not respond enough. However, we are happy to keep the gate open to assist you even after the official three long week, dedicated for KTS.
In order to help you to help us to communicate better, I will duly provide the base/ground for your discussion though this third and last part of the session.

We will remain through the week for two-way communication with ample space to accommodate any input from the subscribers.

NOT ALL the CVM lesions involved to KTS (VM $+\mathrm{LM}+\mathrm{CM}$ ) are warranted for the (interventional) therapy. Indeed, NO therapy with 'close observation' should be considered as THE first option among many- AVM is an EXCEPTION as potentially life/limb threatening lesion but it doesn't belong to KTS as we repeatedly pointed out.

Indeed, absolute majority of VM and LM components of KTS are rarely life-or limb-threatening so that conservative treatments should remain as the first option and only when it is failed, invasive treatment modalities should be considered as next step. Hence, once the diagnosis is fully established including precise assessment of its extent and severity, the outcome of the evaluation should be reviewed by multidisciplinary team together and decide whether the patient should need the intervention or not based on the indications for the therapy.

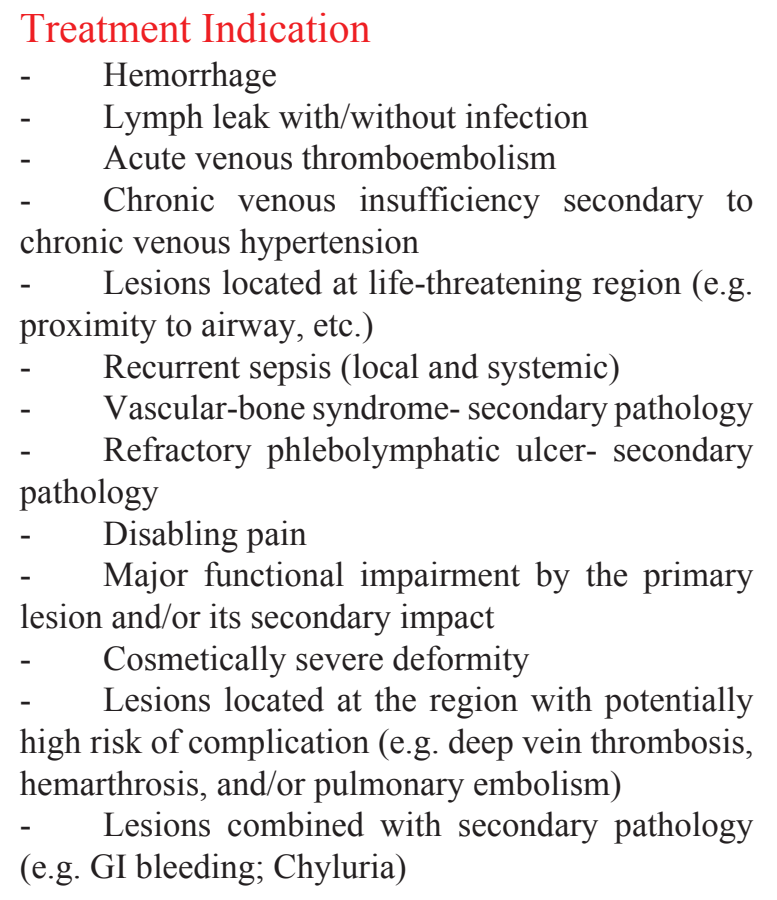

Absolute indications for treatment include hemorrhage, infection, acute thromboembolism, and refractory venous ulcers. Relative indications include pain, functional impairment, chronic venous insufficiency, limb asymmetry due to vascular bone syndrome, and/or cosmetic reasons.

Once the treatment is decided with legitimate indications, the management of CVM lesion per se 
is rather straight forward to go after individual CVM lesion belonging to four different types of VM and LM: Extratruncular VM, Truncular VM, Extratruncular LM, and Truncular LM in addition to CM. But the decision to choose which lesion should go first with priority remains a tricky issue since a variety of CVMs are involved in various extents/severities simultaneously.

Precise assessment of each CVM component is therefore essential not only for appropriate selection of the treatment modality but also for prioritizing treatment among the different CVM lesions.

\section{Conclusion - May 20, 2016}

It has been a quite unique experience for me as well as invited panelists to have such non-stop marathon session dedicated only for KTS issue for the last three week period. So I do sincerely thank to Fausto and Vasculab once again for this opportunity to discuss on this challenging issue of complex nature in depth to help better understanding.

Although Professor Olszewski pointed out 'Lack of even descriptive definition, no imaging helping to differentiate with other malformations and only marginal reports', we believe most of the literatures we provided as references - especially 5 world consensuses on various issues of CVMs- provided sufficient data/ information for 'descriptive definition' of KTS and also for 'differentiate with other malformations' through the first two weeks besides discussions mostly led by the

\section{References}

1) Lee BB, Laredo J, Lee TS, Huh S, Neville R. Terminology and classification of congenital vascular malformations. Phlebology. 2007; 22(6):249-52.

2) Lee BB, Bergan J. Gloviczki P, Laredo J, Loose DA, Mattassi R, Parsi K, Villavicencio JL, Zamboni P: Diagnosis and treatment of venous malformations - Consensus Document of the International Union of Phlebology (IUP)-2009. International Angiology 2009 December; 28(6):434-51.

3) Lee BB, Villavicencio JL: Primary Lymphedema and Lymphatic Malformation: are they the two sides of the same coin? Eur J Vasc Endovasc Surg (2010) 39:646-653

4) Lee BB, Andrade M, Bergan J, Boccardo F, Campisi C, Damstra R, Flour M, Gloviczki P, Laredo J, Piller N, Michelini S, Mortimer P, Villavicencio JL : Diagnosis and treatment of Primary Lymphedema - Consensus Document of the International Union of Phlebology (IUP)-2009. International Angiology 2010 Oct;29(5):454-70.

5) Lee BB, Laredo J. Classification of congenital vascular malformations: the last challenge for congenital panelists. We also dedicated this last third week for its management encouraging more active participation among the subscribers with their own KTS cases, based on various references we provided to meet most of your need.

We certainly hope our attempt to deliver the core issues of KTS has met its goal to make the subscribers feel comfortable to encounter this unique problem of KTS from now on. Indeed, its official session will be over through today, but by all means we are happy to get involved to this issue whenever the subscribers should need further assistance in future, either through Vasculab or my personal emails.

\section{ADDENDUM - May 21-28, 2016}

The Debate will be carried on through another week as Un-moderated session.

\section{Acknowledgements}

The KTrenaunay Vasculab Debate was organized by the Vasculab List as an Online Debate. We thank all the participants for their contribution and especially for their active role: Miguel Angel Amore, Pier Luigi Antignani, Iris Baumgartner, Jean-Paul Belgrado, Lena Blomgren, Alun H Davies, Tom Eaton, Stefano Ermini, Claude Franceschi, S B Gogia, Byung Boong Lee, NingFei Liu, Jovan N Markovic, Raul Mattassi, Nick Morrison, Tom O'Donnell, Waldemar L Olszewski, Sandeep Raj Pandey, Kurosh Parsi, Hugo Partsch, Fausto Passariello, Malay Patel, Sergio Pillon, Teresa Pintos Moreu, Cestmir Recek, Heraldo Schlup, Eva M Sevick, Natarajan Sekar, Gerard Stansby, Massimo Vaghi, David Wright. Finally, we thank Mrs. Iolanda Palma for her organizational effort.

vascular malformations. Phlebology. 2012;27(6):267-9. http:// www.ncbi.nlm.nih.gov/pubmed/22865415

6) Lee BB. Klippel-Trenaunay syndrome:is this term still worthy to use? ACTA PHLEBOL 2012;13(2):83-5

7) Lee BB, Andrade M, Antignani PL, Boccardo F, Bunke N, Campisi $\mathrm{C}$ et al. Diagnosis and Treatment of Primary Lymphedema. Consensus Document of the International Union of Phlebology (IUP)-2013. Int Angiol 2013;32(6):541-74

8) Lee BB, Antignani P.L. Not all the Vascular Malformations are AV malformation! Editorial, ACTA PHLEBOL 2014, 15: 1-2

9) Lee BB. New classification of congenital vascular malformations (CVMs). Reviews in Vascular Medicine. 2015;3(3): 1- 5

10) Lee BB, Baumgartner I, Berlien P, Bianchini G, Burrows P, Gloviczki P, Huang, Y, Laredo J, Loose DA, Markovic J, Mattassi R, Parsi K, Rabe E, Rosenblatt M, Shortell C, Stillo F, Vaghi M, Villavicencio L, Zamboni P. Diagnosis and Treatment of Venous Malformations Consensus Document of the International Union of Phlebology (IUP): updated 2013. Int Angiol 2015;34(2): 97-149. 